
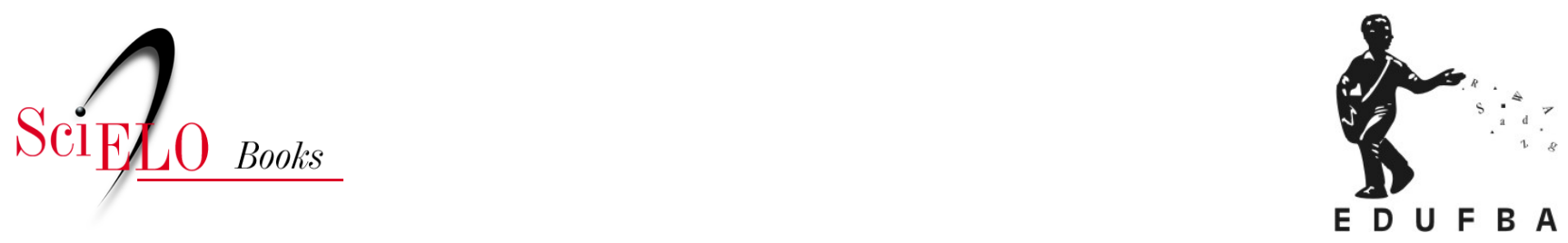

\title{
Escritos \\ Arte e Tecnologia: uma chave para outras educações
}

Nelson De Luca Pretto

\section{SciELO Books / SciELO Livros / SciELO Libros}

PRETTO, N.D.L. Arte e Tecnologia: uma chave para outras educações. In: Educações, culturas e hackers: escritos e reflexões [online]. Salvador: EDUFBA, 2017, pp. 65-76. ISBN: 978-85-232-2019-8. https://doi.org/10.7476/9788523220198.0005.

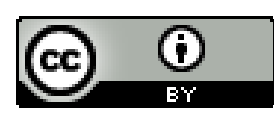

All the contents of this work, except where otherwise noted, is licensed under a Creative Commons Attribution $\underline{4.0 \text { International license. }}$

Todo o conteúdo deste trabalho, exceto quando houver ressalva, é publicado sob a licença Creative Commons Atribição 4.0. 


\section{ARTE E TECNOLOGIA: UMA CHAVE PARA OUTRAS EDUCAÇÕES ${ }^{54}$}

De certa feita, entrei numa galeria em Londres a procura de um livro com uma imagem, uma ideia, para compor o relatório de meu pós-doutoramento que estava prestes a terminar. Estamos em 1998 e a galeria era Serpenty Gallery ${ }^{55}$, um lugar mágico, incrustado no Hyde Park. Lá pude ver - e me apaixonar - imensos quadros, na verdade enormes imagens, do fotografo alemão Andrea Gursky ocupando aqueles espaços que, por sua vez, se misturam aos jardins do Hyde Park. Retorno atrás de catálogos de exposição, coisa que adoro, e me dou de cara com um livro de M.C. Escher, por quem sou verdadeiramente apaixonado, com um enorme turbilhão na frente. O entalhe sobre madeira Whirlpool (turbilhão) é de um movimento espetacular e esse turbilhão não saiu de minha cabeça.

\footnotetext{
${ }^{54}$ Esse texto foi originalmente publicado, com algumas modificações, no seguinte livro: PEDROSA, Fernanda; LEONEL, Juliana Matos. (Org.). Arquivo Oi Kamum! 12 anos: juventudes, experiência e aprendizagens em arte e tecnologia. Rio de Janeiro: Instituto Oi, 2015. p. 61-73. Capítulo escrito especialmente para o livro.

${ }^{55}$ Disponível em: <http://www.serpentinegalleries.org/>. Acesso em: 15 dez.2014.
} 
Nesse mesmo período, estando no bairro de New Cross, na Universidade de Londres, no Goldsmiths College ${ }^{56}$, acompanho o final do ano letivo e vejo os alunos do bacharelado apresentando seus trabalhos. Goldsmiths é uma universidade que vibra e transpira arte, música, artes visuais, teatro. O genial músico John Cale, que participou da primeira formação do grupo Velvet Underground, foi dessa universidade e muitos outros artistas por lá passaram. Os alunos expunham suas criações como trabalhos finais de graduação, numa espécie de exposição aberta. O grande detalhe, segundo uma fiel observadora que por lá estava e com quem conversei, era: os marchands já estavam, desde uns três ou quatro anos, comparecendo a esses eventos para comprar os produtos realizados pelos alunos. $\mathrm{O}$ que antes acontecia basicamente com os trabalhos dos mestrandos, agora já chegava à graduação. E, claro, os próprios produtos começaram a olhar para os marchands, para as galerias, para o sucesso e, claro, também eles, para o mercado!

Em um salto mais atrás no tempo, me vem à mente o trabalho que fazíamos no bairro do Maciel (muitos nem sabem que no conhecido Pelourinho, em Salvador, existia uma área, um sub-bairro, com esse nome, cheio de gente, interessada em arte e cultura. Foi lá que nasceu o bloco Olodum!). À época, eu coordenava o programa educacional da Fundação do Patrimônio Histórico da Bahia, hoje Instituto do Patrimônio Artístico Cultural da Bahia (IPAC). Buscávamos introduzir no cotidiano daquele sofrido bairro -, que não tinha ainda sido remodelado e seus moradores de lá ainda não tinham sido expulsos - arte, cultura, lazer e, claro, muita alegria para a vida sofrida daqueles meninos e meninas. Lembro também, mais atrás ainda e na mesma região da cidade, da ação do fotógrafo Rino Marconi, com um belo trabalho, ensinando os princípios da câmara escura, usando latas com buracos no fundo, fazendo com que a meninada pudesse ter o prazer de ver a sua área e suas gentes registradas, guardadas para o presente e o futuro, através de imagens feitas por eles mesmos. Onde estarão essas imagens?!

\footnotetext{
${ }^{56}$ Disponível em: <http://www.goldsmiths.ac.uk>
} 
Não tínhamos ainda a profusão de aparelhos digitais dos dias de hoje... Imperava o analógico e a escassez de informações.

Pensando agora, ao escrever esse texto para comemorar os 10 anos de atuação do programa Oi Kabum e suas quatro marcantes experiências pelo Brasil sobre todas essas coisas já vividas, me pergunto e tento responder: - o que essas minhas lembranças têm de comum e de distintas? No que elas nos ajudam a pensar os projetos e as vivências da Oi Kabum ontem, hoje e o que podemos vislumbrar para o futuro?

Arrisco dizer que, de comum, têm a importância de dar vazão à criação, à inventividade, à explosão de ideias que emanam de cada uma dessas crianças, jovens e adolescentes, amanhã adultos. Têm em comum, esses turbilhões criativos que explodem aqui na Bahia, Minas, Pernambuco, Rio, na Inglaterra, Alemanha e em todos os lugares do mundo onde a liberdade de expressão e de criação impera. De distinto, pelo menos, um alerta inspirado no caso vivenciado em Londres, onde a presença do mercado da arte já se aproximou da universidade - da escola - e passou a ficar mais perto do processo criativo. Um mercado poderoso que não mede esforços para comandar as criações. Por isso, parece importante provocar reflexões que nos possibilitam pensar os processos formativos, sem perder de vista o mundo do trabalho - vejam que não me refiro só ao mercado, falo do mundo do trabalho, numa visão mais ampla -, mas que dele não seja tão próximo, a ponto de permitir que essa dimensão profissional e do tal mercado termine implicando uma perda do espaço para a criação. Nesse campo, todo cuidado é pouco.

Penso que todo o processo de formação profissional precisa estar fortemente associado à ideia de que o mercado não pode ser o definidor de tudo, como pensam e querem muitos dos analistas do próprio mercado. Escola é espaço de criação. E, sendo assim, não pode se contentar apenas com reprodução e o consumo das informações e de conhecimentos já estabelecidos. Tem que ser um espaço - e é um espaço privilegiado onde os processos criativos estejam presentes de forma intensa, dialogando com o instituído. Inclusive, fazendo a crítica ao mercado. Assim, esta escola, estará, de fato, formando cidadãos que passam a programadores da produção (e da sociedade) e não a meros reprodutores. Estamos nos refe- 
rindo à formação de jovens com seus 15, 16, 17 anos de idade, portanto, uma turma já além da formação básica que está, também, sendo impelida a pensar sua própria sobrevivência e, assim, em possibilidades formativas que lhe deem oportunidades de trabalho. Por conta dessa dupla dimensão é que não podemos descuidar, pois queremos, antes de tudo, que essa juventude vislumbre a sua realização profissional, mas também e, principalmente, existencial.

Em outra impressionante exposição, abrigada no museu Quai Braily $^{57}$, em Paris, chamada Os mestres da Desordem (Les maitres du desor$d r e)^{58}$, o tema da criação, mais uma vez, apareceu com força total. Depois de um belíssimo e interessante percurso, o navegador chega a uma instalação do artista francês Ben Vautier, denominada Não existe arte sem desordem (pas d'art sans desordre). De acordo com site da exibição, o que se quis foi trazer para o debate "[...] a presença de desordem, inscrita num panteão de nossas crenças e culturas, desde Dionísio até Set Tifón, e por técnicos, xamanes e outros intermediários chamados de 'mestres da desordem', encarregados das negociações com as forças do caos”. E continuava: "Neste compromisso permanente entre turbulência e razão, os ritos são a forma privilegiada de negociação com as potências que governam as sociedades humanas. Paralelamente a estes rituais sagrados, as festas, bacanais, carnavais ou festas de loucos que parecem ser outro meio, profano, que autoriza o desencadeamento das pulsões transgressoras." Vendo a exposição e lendo esses trechos do seu catálogo, tenho me perguntado, da mesma forma que Ben Vautier afirmava que não existe arte sem desordem, se também para a formação contemporânea dos nossos jovens não temos que avançar na busca de uma escola mais centrada no caos do que na ordem. Ou seja, pode existir educação - e escola! - sem desordem?

A questão não é fácil, pois a escola, desde os seus primórdios, teve a função de adequar as crianças e jovens ao mundo dos adultos, ao universo culto. Mas como isso vem sendo feito e como pode ser feito, se temos

\footnotetext{
${ }^{57}$ Disponível em: <http://www.quaibranly.fr/>

${ }^{58}<$ http://www.quaibranly.fr/es/programmation/exposiciones/esposiciones-pasadas/los-ma estros-del-desorden.html>. Acesso em: $31 \mathrm{dez} .2014$.
} 
um mundo em constante e veloz transformação, como o que hoje estamos vivendo?

Aqui volta para o texto e para o contexto, a experiência da $\mathrm{Oi}$ Kabum. Um espaço de criação, até bem pouco tempo, apenas complementar da escola formal - e que traz para os jovens que a oportunidade de, efetivamente, criar e inventar. Ou seja, transformar radicalmente os processos formativos, com ênfase na autoria e não na mera reprodução do instituído. Entra em cena nesses processos formativos, muito mais a presença da desordem do que da ordem, muito mais a ideia de articular todos os conceitos e saberes do que a (não) simples apreensão de conhecimentos. Superar a educação bancária - tão bem definida por Paulo Freire em vários dos seus trabalhos - já é algo que não está em discussão. Ninguém mais - pelo menos no discurso - acredita que um jovem que chega à escola seja uma tábula rasa que precisa ser preenchido com informações e conhecimentos. Mas, na prática, o que temos visto e acompanhado em nossas pesquisas e intervenções, é que, mesmo tendo clareza de que essa perspectiva de educação não pode ser a base da escola, os processos formativos não trazem para o seu cotidiano - e, portanto, para dentro da escola - os saberes, as capacidades e habilidades dos jovens. E hoje, mais do que nunca, as tecnologias de informação e comunicação - operadas pela juventude de forma impressionante - trazem tudo isso para dentro da escola, fazendo com que ela, mesmo a contra gosto dos gestores, seja sem muros, sem limites ou, pelo menos, com seus limites esgarçados.

Dessa forma, os processos coletivos, que são ricos pela sua própria natureza e cada vez mais necessários em função da ênfase individualista imposta pela sociedade do mercado, continuam sendo afastados dos instituídos processos educacionais escolares. Isso demanda que tragamos para o interior da escola uma dimensão que nos parece fundamental: a importância do coletivo e do colaborativo nos processos formativos.

Essa ideia de produção colaborativa e compartilhada, já bastante mencionada no capítulo anterior, ao nos referirmos ao desenvolvimento da computação, dos movimentos do software livre e do código aberto, dos hackers e de sua cultura. 
Tudo a ver com o que vimos acontecer nos projetos da Oi Kabum? Acho que sim.

Reescrevo aqui a partir do que já escrevi anteriormente, pois creio que se aplica e pode nos ajudar nesta reflexão sobre as experiências das quatro escolas Oi Kabum!, as quais foram analisadas no livro comemorativo do qual esse capítulo fez parte, a partir de diversos olhares ${ }^{59}$. Steven Levy ${ }^{60}$ aponta seis princípios orientadores de todo o trabalho desses apaixonados pela computação e criação. Segundo ele, esses princípios explicavam o bom desenvolvimento desses clubes e de seus projetos. O primeiro princípio é pensar que o acesso aos computadores deveria ser total e ilimitado. Mais do que computadores, deveria ser liberado o acesso a qualquer coisa que pudesse ensinar a você alguma coisa sobre como o mundo funciona. Segundo, toda informação deve ser livre (free) porque se você não tem acesso a ela não terá como consertar as coisas. Aqui é importante lembrar que, em inglês, a palavra free pode tanto significar livre quanto grátis, o que nos permite considerar que toda informação deve ser livre e gratuita. O terceiro princípio está relacionado a uma desconfiança das autoridades por parte dos hackers. E, assim, estimulam-se procedimentos pouco burocráticos e descentralizados. A descentralização passa a ser a palavra de ordem. O quarto princípio: o julgamento de um hacker é feito pela qualidade do que ele efetivamente faz e realiza e não por critérios "falsos", como escolaridade, idade, raça ou posição. Confrontando a dureza aparente das máquinas, o quinto princípio está relacionado à crença na possibilidade de se "[...] criar arte e beleza num computador"61. Por último, e não menos importante, o sexto princípio: os computadores podem fazer a vida melhor.

Esse conjunto de elementos éticos, orientadores do trabalho dos hackers, foi gerado de forma coletiva e aberta, criando os computadores, expandindo as redes de computadores e promovendo o nascimento da internet. São justo estes princípios que hoje nos inspiram a pensar nas necessárias transformações para a educação!

\footnotetext{
${ }^{59}$ PEDROSA; MATOS, Op. cit.

${ }^{60}$ LEVY, op.cit., p. 26.

${ }^{61}$ LEVY, op. cit, p. 29.
} 
Aqui vale recordar que só temos a internet como a conhecemos hoje graças aos seus pioneiros que, compreendendo a sua importância, decidiram simplesmente liberar as suas criações para que o mundo pudesse utilizá-las e aperfeiçoá-las. Se Theodoro Nelson, Vannevar Bush, Norbert Wiener, Alan Turing, Ada Lovelace, Tim Bernes-Lee, entre tantos outros, tivessem simplesmente patenteado suas criações ou licenciado suas implementações em software sob licença não permissiva, muito provavelmente nada do que hoje estamos vendo e vivendo estaria acontecendo. Sem dúvida, não era isso o que desejaríamos.

Indo mais adiante, trago, mais uma vez, Pekka Himanen. Analisando o trabalho dos apaixonados pela computação, ele definiu sete características dessa ética: paixão, liberdade, valor social (abertura), nética (ética da rede), atividade, participação responsável e criatividade. ${ }^{62} \mathrm{~A}$ partir dele, podemos, então, pensar que essa postura hacker pode ser em última instância uma postura para todos os campos das atividades humanas. Evidentemente isso cai como luva para pensarmos nas escolas e nos processos educacionais. Pekka Himanen mencionou que só conhecia duas profissões que seguem essa ética: os artistas e os acadêmicos. Para nós, em diálogo com Karla Brunet para a elaboração deste texto, as experiências da Oi Kabum! conseguem reunir hackers, artistas e acadêmicos, sendo, portanto e quem sabe, uma boa pista para pensar mais profundamente nos processos educacionais e nas necessárias transformações da escola.

Tudo isso porque esses princípios dos hackers possibilitaram a construção do ciberespaço e não podem ser simplesmente incorporados à escola como meras ferramentas auxiliares das atividades, como já mencionei antes e voltarei a tratar. Os aparatos tecnológicos digitais, por sua vez, intrinsecamente permitiram a emergência de novas linguagens e de novas práticas de produção de conhecimentos e de culturas. E com esta reflexão voltamos a destacar a importância de produção e circulação colaborativa de conhecimentos, saberes e culturas.

Esse desenvolvimento coletivo e colaborativo foi sendo impulsionado por uma série de iniciativas das quais, o já referido movimento do

\footnotetext{
${ }^{62}$ HIMANEN, P. A ética dos hackers e o espírito da era da informação. Rio de Janeiro: Campus; São Paulo: Editora 34, 2001. p. 125-127.
} 
software livre pode ser considerado um importante exemplo, e que desembocou na criação de sistemas operacionais o GNU/Linux e seus diversos aplicativos, bem como em processo de produção de conteúdo colaborativo, sendo a Wikipédia seu exemplo mais visível e, com certeza, mais significativo. Seria impossível, imaginar, algumas décadas atrás, a criação de uma enciclopédia livre, onde, potencialmente, qualquer um contribuísse com a sua escrita. No entanto, hoje a Wikipédia é construída em 260 idiomas $^{63}$, ten mais de 861 páginas de conteúdo em português ${ }^{64}$, mais de 4 milhões e meio de páginas em inglês, crescendo numa razão de 800 por dia. ${ }^{65}$

Tudo isso significa a ampliação de uma dimensão que me parece fundamental para os processos educativos: a montagem das redes, com o estabelecimento de múltiplas e diversas conexões, sejam elas as tecnológicas ou as promovidas pelos encontros entre as pessoas. Falamos aqui em redes de produção, de produção de conteúdos e de significados, conectando pessoas distantes, países distintos e lugares separados geograficamente e, também, conectando temas às vezes não tão próximos. Em outros momentos, as conexões se dão entre temas, pessoas, países e tempos, tudo conectado.

Mas para que isso aconteça, precisamos ter bem definidas as concepções que temos para a educação e para as próprias tecnologias. Para a educação, já mencionamos, precisamos partir de uma concepção autoral, com a forte valorização dos saberes para, apropriando-se das tecnologias, poder conectar o local com o planetário. E aí, enfrentamos o grande desafio que é compreender as tecnologias, especialmente as de informação e comunicação, para além da mera dimensão instrumental. O que temos observado é que há uma insistência em incorporá-las aos processos, principalmente no campo da educação, tentando encaixá-las em concepções que a aprisionam em grades conceituais que não possibilitam o caminhar

\footnotetext{
${ }^{63}$ Disponível em: <http://pt.wikipedia.org/wiki/Wikip\%C3\%A9dia:Wikip\%C3\%A9dia_em_ outras_l\%C3\%Adnguas>. Acesso em: 4 jan. 2015.

${ }^{64}$ Disponível em: <http://pt.wikipedia.org/wiki/Wikip\%C3\%A9dia:Estat\%C3\%Adsticas>. Acesso: 4 jan. 2015.

${ }^{65}$ Disponível em: <http://en.wikipedia.org/wiki/Wikipedia:Statistics>. Acesso em: 4 jan. 2015.
} 
mais solto e mais amplo, característico da hipertextualidade e da cibercultura.

Assim, na maioria das vezes, as tecnologias digitais - e a internet em particular - são tratadas como meras ferramentas auxiliares dos processos educacionais. Isso sem dúvida é de um enorme reducionismo e, o mais grave, não contribui para as necessárias transformações que necessitamos para a educação. Tenho insistido nisso desde a década de 1990 do século passado e comecei a escrever sobre o tema a partir de minha tese de doutorado, transformada no livro Uma escola sem/ com futuro: educação e multimídia, inicialmente publicado pela Papirus e, depois de sete edições, relançado pela Edufba em 2013, com licenciamento livre. ${ }^{66}$ Observe que o jogo de palavras que fiz no título $(\mathrm{sem} / \mathrm{com})$ para o futuro da educação foi justamente para ressaltar as possibilidades do uso das tecnologias. Se apenas instrumental, seria, com certeza, a sua exclusão da escola, no futuro e até no presente da escola. Uma escola para o presente e com futuro é a escola que reconheça a capacidade das juventudes (como gosta Juarez Dayre ${ }^{67}$ e eu também!) e das tecnologias para fortalecer a dimensão autoral de cada jovem, no coletivo e no individual, tudo articulado de forma intensa pelas redes, tecnológicas ou não.

Assim, sem desconhecer os processos individuais, penso ser importante fortalecer os processos autorais em rede, que combinam, conforme afirma Beatriz Cintra Martins em seu livro Autoria em rede, "[...] o coletivo, a obra aberta e inacabada, com um traço também individual herdado também da cultura do livro e adequado à economia da dádiva, formando uma nova configuração que não corresponde à dissolução completa do autor, mas também não à autoria individualizada". ${ }^{68}$

Voltemos, pois a falar um pouco de escola, afinal, a Oi Kabum é uma escola! Pensando em todas essas questões, necessário se faz, penso eu, olhar a escola com outros olhos. Tanto o olhar de dentro, de dentro para

\footnotetext{
${ }^{66}$ PRETTO, N. De. L. Uma escola sem/com futuro: educação e multimídia. 8. ed. rev. e atual. Salvador: Edufba, 2013.

${ }^{67}$ Professor da Universidade Federal de Minas Gerais e um esmerado pesquisador sobre o tema das juventudes.

${ }^{68}$ MARTINS, B. C. Autoria em rede: os novos processos autorais através das redes eletrônicas. Rio de Janeiro: Mauad, 2014. p. 52.
} 
dentro mesmo, como o olhar de fora, e aí estamos a falar de políticas públicas. A escola, nesse contexto, e enfatizo aqui o sistema público de educação, ganha especial destaque enquanto espaço físico, tecnologicamente equipado para se constituir em uma verdadeira plataforma de integração e articulação da juventude. Esse espaço físico tem que ser valorizado, pois nesse universo de tantas interações em rede, as relações presenciais precisam também ser fortalecidas. Gosto do filósofo italiano Gianni Vattimo quando, em entrevista ao sociólogo e jornalista argentino Ivan Schuliaquer ${ }^{69}$, afirma que vivemos uma sociedade da emancipação, por suposto, com uma proliferação de informações, mas que, justo por isso, é também um sociedade que demanda de nós a vivência em agrupamentos sociais, políticos, porque necessitamos de uma conversa com amigos. E eu acrescento que necessitamos do espaço da escola, uma vez que no coletivo propiciado por estes espaços temos a ajuda para "[...] interpretar a comunicação em rede, a mídia, os jornais”. Para Vattimo, sem esses espaços mais coletivos, não nos orientamos e nos transformamos em "sujeitos sem subjetividade" 70 . Penso que as escolas, esses espaços singulares, promovendo interações entre os sujeitos, entre si e com as tecnologias, promovem a convivência dos múltiplos contextos e das múltiplas subjetividades inerentes à espécie humana, configurando-se tanto como lugares específicos como possibilidades de conexões com outros lugares, esses também específicos, promovendo outros entrelugares, fruto dessas relações singulares. Estes, por sua vez, "[...] são instáveis, pois decorrem da ressonância do diálogo de dois lugares, que ressaltam na precipitação de acontecimentos produzidos pelo diálogo [dos diferentes, acrescento]; ao terminar a ressonância, o entrelugar se esvai, mas os dois lugares que precipitam os acontecimentos ressonantes agregam conhecimento", como afirmou Luiz Felippe Serpa em seus escritos nos nossos Rascunhos digitais. ${ }^{71}$

Tecnologias, diálogos entre lugares, com valores culturais fortalecidos, fortalecem a perspectiva autoral que tenho insistido para cada um

\footnotetext{
${ }^{69}$ SCHULIAQUER, I. El poder de los medios: seis intelctuales en busca de definiciones. Buenos Aires: Capital Intelectual, 2014.

${ }^{70}$ id., ibid., p.27.

${ }^{71}$ SERPA, L. F. P. Rascunho digital: dialógos com Felippe Serpa. Salvador: Edufba, 2004. p. 166.
} 
e para a escola no seu coletivo. Com esta perspectiva autoral que, acrescento, deve ser também ativista, podemos perceber o quanto nos apropriamos das tecnologias e as transformamos. Ampliou-se no mundo todo o acesso à internet, houve uma vertiginosa queda nos preços dos equipamentos digitais e, dessa forma, a produção das imagens e das informações deixou de restringir-se aos grandes conglomerados midiáticos e passou a ser prerrogativa de qualquer um, pelo menos potencialmente. Parece que justo isso vem sendo feito nas experiências das escolas Oi Kabum e que não pode ser perdido. Fortalecer esses movimentos é básico para a sobrevivência da escola. Ela precisa estar conectada (e aí a luta política é de cada um em particular e de todos nós no coletivo) e também preparada para tratar e fortalecer os seus valores locais, de forma a promover a interação do local com o planetário. As escolas precisam, então, se constituir em espaços vivos de estímulo à produção e à comunicação e, com isso, promover um forte diálogo e um aprendizado da Cultura (com C maiúsculo) e da Ciência (também com $\mathrm{C}$ maiúsculo), essas que já tradicionalmente estão presentes e sendo ensinadas nas escolas. Aqui, elas (a Ciência, a Cultura, os conhecimentos estabelecidos, enfim) ainda estarão presentes, mas dentro de outra perspectiva, uma vez que passam a dialogar mais intensamente com os saberes locais, constituindo aquilo que venho insistindo ao longo dos últimos anos: a promoção de um círculo virtuoso de produção de culturas e conhecimentos. Instala-se, assim, um intenso diálogo entre o conhecimento da comunidade com o universal. O saber local passa a dialogar com o conhecimento instituído e, a partir disso, passa a ser reconstruído no tal círculo virtuoso que acabo de mencionar, e vice-versa. Instala-se a remixagem total.

Para encerrar, trago uma bela fala extraída de uma conversa com Mãe Beth de Oxum, do Recife, Pernambuco, em um debate dentro da nossa disciplina Polêmicas Contemporâneas ${ }^{72}$, na Faculdade de Educação da

\footnotetext{
${ }^{72}$ Disponível em: <http://www.polemicas.faced.ufba.br>. Para conhecer mais sobre essa experiência ver o o artigo: PRETTO, Nelson De Luca. Polêmicas contemporâneas: formando professores ativistas comprometidos com a sociedade. Revista Observatório, v. 3, n. 4, p. 32-55, jul. 2017. doi: https://doi.org/10.20873/uft.2447-4266.2017v3n4p32. Disponível em: $<$ https://sistemas.uft.edu.br/periodicos/index.php/observatorio/article/view/3447>. Acesso em: 28 jul. 2017.
} 
UFBA, quando afirmou, ao falar dos desafios do uso das TIC nos movimentos sociais: $\mathrm{O}$ momento da tecnologia é um achado muito importante e ali tem uma chave prá ser rodada. Essa chave está em nossas mãos, mas precisamos ter as condições para usá-la. Outro pernambucano nos ajuda nessa reta final. Trata-se de Lenine que, ao comemorar os seus 30 anos de carreira, afirmou ser um artista raiz e antena ao mesmo tempo. ${ }^{73}$

Essas juventudes estão sedentas por outra escola, por outras escolas, aqui também na perspectiva plural, e querem, elas também, ser raiz e antena; elas querem pegar a chave pra ser rodada e, com isso, juntando tudo: artes, ciências, saberes, tecnologias, solidariedades, generosidades, ajudar a construir outras educações.

\footnotetext{
${ }^{73}$ Disponível em: <http://www.dw.de/lenine-comemora-30-anos-de-carreira-sou-raiz-mas-
} tamb\%C3\%A9m-sou-antena/a-17043935>. Acesso 18 dez. 2014. 